Instituto Internacional de Investigación y Desarrollo Tecnológico Educativo INDTEC, C.A.

DOI: https://doi.org/10.29394/Scientific.issn.2542-2987.2018.3.8.2.39-58

OAI-PMH: http://www.indteca.com/ojs/index.php/Revista Scientific/oai

\title{
Programa Formativo de Educación en Salud sobre la Enfermedad del Chikungunya
}

Autora: Carmen Yorlet Escalona Belandria Universidad Pedagógica Experimental Libertador, UPEL marlenism3@gmail.com Barinas, Venezuela

\section{Resumen}

El objetivo de la investigación fue aplicar un programa de formación en educación para la salud a la comunidad "Juan Pedro del Corral", municipio Barinas, estado Barinas, en la prevención de la enfermedad del Chikungunya. El estudio responde metodológicamente al paradigma cualitativo. El tipo de estudio en una investigación acción y el diseño de campo. Se consideraron siete (07) informantes clave. La técnica e instrumento que se utilizó en la recolección de la información fue la observación directa y como instrumento una entrevista en profundidad. El estudio permitió concluir: La gran mayoría de los entrevistados tienen desconocimiento de la enfermedad del Chikungunya; así como también el agente transmisor. Sin embargo, manejan el conocimiento que el agente trasmisor es un zancudo infectado. Los informantes señalaron que los síntomas de la enfermedad están enmarcados en dolor de cabeza, fiebre, erupción en el cuerpo y dolores articulares y los medicamentos utilizados para aliviar la misma fue el acetaminofén. También, informaron que dicha enfermedad se complica con otras enfermedades. El programa de formación para la salud representa un aspecto importante en el desarrollo del individuo porque incide en la integración y participación de las acciones ambientales en la cual se desenvuelve dicho individuo. Se planificaron un conjunto de actividades inherentes a mejorar, informar y educar a la comunidad en la prevención de la enfermedad del Chikungunya.

Palabras clave: formación; salud; enfermedad. 


\title{
Health Education Training Program on Chikungunya Disease
}

\begin{abstract}
The objective of the research was to apply a training program in health education to the community "Juan Pedro del Corral", Barinas municipality, Barinas state, in the prevention of Chikungunya disease. The study responds methodologically to the qualitative paradigm. The type of study in an action research and field design. Seven (07) key informants were considered. The technique and instrument used in the collection of the information was direct observation and as an instrument an in-depth interview. The study allowed to conclude: The vast majority of the interviewees have ignorance of Chikungunya disease; as well as the transmitting agent. However, they handle the knowledge that the transmitting agent is an infected mosquito. The informants indicated that the symptoms of the disease are framed in headache, fever, rash in the body and joint pains and the medications used to relieve it was acetaminophen. They also reported that this disease is complicated by other diseases. The training program for health represents an important aspect in the development of the individual because it affects the integration and participation of the environmental actions in which the individual develops. A set of inherent activities was planned to improve, inform and educate the community in the prevention of Chikungunya disease.
\end{abstract}

Keywords: training; health; disease. 


\section{Introducción}

La salud como proceso de capacitación de la comunidad para actuar en la mejoría de su calidad de vida y de salud, incluso un mayor control sobre ese proceso. No obstante, para alcanzar un estado de completo bienestar físico, mental y social, individuos y grupos deben ser capaces de identificar sus aspiraciones, satisfacer sus necesidades y cambiar o saber manejar el medio ambiente. Esto significa controlar los factores políticos, económicos, sociales, culturales y ambientales, los cuales incluyen: habitación, educación, alimentación, renta, acceso a los servicios de salud, ecosistema estable, recursos sustentables, justicia social, y otros.

Por lo tanto, en toda sociedad, los procesos de cambio de carácter más amplio están permanentemente relacionados con procesos que involucran los individuos en su práctica cotidiana. En este sentido, la Educación para la Salud es importante, cuando se piensa en la formación y capacitación de los profesionales de salud.

Se parte de la suposición que las metas que tengan como objetivo mejorar la calidad de vida de un país o región, solamente podrán ser alcanzadas si las medidas de orden política son combinadas con acciones específicas en el interior de las instituciones, sobre todo en los servicios de salud, y otros sectores en los cuales la educación para la salud sea relevante: escuelas, empresas, sindicatos, asociaciones de barrio, comunidades religiosas, y otros.

La Organización Mundial de la Salud, citado por Perea (2001): define la educación para la salud como "el estado de bienestar, físico, mental y social" (pág. 24). Esto refiere a la etapa en la cual individuo se encuentra en buen estado de manera emocional, intelectual, corporal en interacción con el contexto en que se desenvuelve. Las personas se mueven de un lado a otro día tras día, no hay límite señalado para este proceso. Hay un entorno muy amplio en que la gente puede estar dentro de la salud o de la enfermedad. El 
estado de salud no es constante, sino variable. La salud preventiva incluye todos los procesos y vivencias humanas que apuntan hacia el desarrollo integral del individuo, desde la conciencia de su cuerpo hasta la toma de conciencia de sus relaciones personales y trascendentales.

La educación para la salud es uno de los instrumentos para promover e implementar su acción preventiva. Ayuda a los ciudadanos o grupos a adquirir conocimientos sobre los problemas de salud y sobre los comportamientos útiles para alcanzar su objetivo. La prevención de salud significa reducir los riesgos que la amenazan y modificar los comportamientos que la afectan. El mejoramiento de la salud reduce la pobreza y hace posible el crecimiento.

En consecuencia, las sociedades han venido evolucionando de manera acelerada, por lo que los países se han preocupado por prepararse para aprovechar el potencial del conocimiento humano en su desarrollo económico y social, promoviendo una educación y una cultura para la creatividad, la disciplina y el trabajo. En tal sentido, hay una creciente convicción de que la educación es el elemento clave para enfrentar los nuevos retos y lograr una mejor producción y distribución de los bienes y servicios que la sociedad genera. Desde esta perspectiva, señala Santander (2010), que:

La educación ha de entenderse en los nuevos tiempos, como la expresión condensada de identidad nacional y sapiencia, construyendo un ser social que reconozca su localidad y pueda extraer de ella los elementos necesarios para crear un punto de vista universal que lo proyecte como sociedad. (pág. 66).

Interpretando al autor, la educación en tiempos postmodernos está inmersa en el sentir o pertenencia de una colectividad de sus valores, creencias y costumbres a través del conocimiento de sociedad en función de profundizar en lo local, con miras a una sociedad futurista, universal, en paz y convivencia de cada uno de los ciudadanos y ciudadanas del país. Además, conscientes, socializados y sensibilizados hacia la globalización de las 
acciones en beneficio de la calidad de vida.

Por otra parte, en Venezuela, en el caso del subsistema de Educación Primaria, en la actualidad busca concentrar o elevar la calidad educativa en actividades inherentes al trabajo, a la vida cotidiana del estudiante, en aprendizajes significativos, efectivos y acordes con la convivencia de los alumnos de acuerdo con el entorno geográfico y social de la comunidad donde está ubicada la escuela, es decir a la realidad muy cercana de los mismos. Refiere Cárdenas (2010):

Una acción prioritaria para asegurar una educación primaria de calidad, donde los alumnos comiencen a valorar los recursos naturales y patrimonios culturales como potenciales alternativas para el logro de un avance económico y sustentable de su comunidad, es la oportuna y acertada articulación curricular con la educación ambiental y el desarrollo endógeno, el cual tiene como misión en la Educación Bolivariana, la integración de manera natural de la sociedad en su complejidad cultural, social e institucional. (pág. 88).

Es así como esta visión de la educación ambiental se genera como estrategia dentro del contexto de la educación, como un continuo humano en el cual la escuela y comunidad son simultáneamente objeto y sujeto de desarrollo, creando sentido de pertenencia a la realidad social y educativa, buscando la integración de los actores sociales de la misma, con el fin de lograr la construcción de un sistema educativo que alcance un desarrollo integral y de calidad, que permita superar las necesidades y expectativas de la escuela y la comunidad, al abrir espacios de encuentro para la integración, buscando y analizando oportunidades que permitan establecer un diagnostico confiable $y$, en consecuencia una manera de actuar para asumir los desafíos de la sociedad dinámica actual.

Por otra parte, La Organización Panamericana de la Salud y La Organización Mundial de la Salud (OMS, 2009a): "han realizado numerosos trabajos científicos que han aportado datos acerca del conocimiento de la 
biología y ecología de enfermedades endémicas, por los vectores que genera el mosquito Aedes albopictus" (pág. 74). Estos estudios han permitido crear programas de vigilancia y control de este vector, que ha conllevado que en algunos países a erradicar y controlar las enfermedades.

Por su parte, Duanes (2010): indica que "el primer virus del chikungunya fue identificado en 1953 y este virus es un alfa arbovirus, aedes, mosquitos, responsable por el primer y poco documentado, dicha enfermedad aguda que se registró en el trópico" (pág. 7). El principal síntoma es la fiebre, erupción, debilidad. La epidemia fue una sorpresa ya que esta es una inesperada emergencia, en magnitud, es un caso clínico muy raro o jamás descubierto anteriormente. Se observa que el virus fue reconocido en la década de los cincuenta hacia la parte del trópico, se proliferó de manera inesperada porque se desconocía de su existencia.

En este contexto, La Organización Mundial de la Salud (OMS, 2009b): expone que "el Virus Chikungunya es un visitante nuevo en las Islas del Caribe, Sur América y Centro América. El 11 de julio del 2014, La Organización Panamericana de la Salud (OPS) ya había declarado la presencia de casos autóctonos en estas regiones" (pág. 11). Es decir, personas que no habían viajado y que se habían enfermado. La forma de haber adquirido la enfermedad no podría ser otra, sino, que un Aedes de la región infectado, lo hubiese picado.

En Venezuela las condiciones de saneamiento ambiental y de hacinamiento en muchos sectores de la población, han permitido la proliferación del mosquito causante de enfermedades endémicas, cuya mortalidad ha ido en aumento y ésta se traduce en un problema que hay que enfrentar y solucionar. Es decir, no sólo el riesgo que implica para la salud de los venezolanos, si no el elevado costo que, en términos de atención ambulatoria, hospitalización y mantenimiento de las medidas de prevención y control de los vectores, Gómez (2012a), plantea: 
El 15 de Julio el estado venezolano informa que lleva 45 casos registrados de los cuales 2 estaban siendo estudiados por qué no se había identificado salida del país. El día 19 de julio, en apenas 4 días ya Venezuela anuncia que llevan registrado 57 casos de fiebre por el Virus y que de estos 7 son transmitidos en el País, específicamente en el Estado Vargas. (pág. 4).

Se observa que es alarmante, como se ha ido incrementando las cifras de ciudadanos y ciudadanas con el padecimiento de este virus. Hoy día el mosquito Aedes albopictus se ha convertido en Venezuela en un causante de enfermedad epidemiológica que afecta a los habitantes, la cual es conocida como chikungunya, Gómez (2012b), manifiesta:

Su modo de infección es a través de un virus el cual lo trasmite causando fuerte afección en las articulaciones. La chikungunya (en idioma makonde: chikungunya, pronunciado /,tJikən'gunə/), conocida además como «Artritis epidémica chikunguña» 0 «Fiebre de chikungunya» (abrev.: CHIK), es un virus transmitido por artrópodos, del género alfavirus, que se transmite a las personas mediante la picadura de los mosquitos portadores Aedes; tanto el Aedes aegypti como el Aedes albopictus. (pág. 23).

Interpretando la cita, anteriormente planteada, la enfermedad se manifiesta de una manera dolorosa porque afecta las articulaciones de los individuos, en muchos de los casos propiciando la inmovilidad de los mismos; además la patología se presenta con excesivo aumento de la temperatura y brotes en la piel.

Toda esta situación, no es ajena a los habitantes de la comunidad Juan Pedro del Corral, municipio Barinas, estado Barinas, porque quienes integran el contexto son seres humanos que por las características de salubridad de la zona existen focos para proliferación del mosquito Aedes albopictus. Asimismo, no se ha generado la concienciación de medidas preventivas, control y saneamiento en la mencionada comunidad. En vista que no se aprecia en ningún momento procesos de fumigación y limpieza de los espacios 
tanto públicos como privado.

El estudio planeta las siguientes interrogantes de investigación: ¿Cuál es la situación existente en la comunidad Juan Pedro del Corral sobre la enfermedad del Chikungunya?, ¿Cómo será el programa de formación en educación para la salud a la comunidad Juan Pedro del Corral en la prevención de la enfermedad del Chikungunya?, ¿Cuáles son los fundamentos teóricos del programa de formación en educación para la salud y la prevención de la enfermedad del Chikungunya?; ¿Cuáles son los elementos en la formulación del el programa de formación en educación para la salud a la comunidad Juan Pedro del Corral en la prevención de la enfermedad del Chikungunya.?, ¿Qué mecanismos se emplearán en la Operacionalización del programa de formación en educación para la salud a la comunidad Juan Pedro del Corral en la prevención de la enfermedad del Chikungunya? Planteándose como propósito general aplicar programa de formación en educación para la salud a la comunidad "Juan Pedro del Corral", municipio Barinas, estado Barinas, en la prevención de la enfermedad del Chikungunya

\section{Antecedentes, Teoría y Conceptos}

\subsection{Antecedentes}

Son las investigaciones realizadas anteriores a ésta, por lo tanto, constituyen los resultados de la intervención de las variables que se consideran para el estudio, de otras investigaciones que la anteceden. Según la Universidad Pedagógica Experimental Libertador (2016): expresa que están "referidos a trabajos de Grado, Tesis e Investigaciones desarrolladas (Nacionales y/o Internacionales), con títulos similares y relacionados al de la investigación que se esté desarrollando: es decir, información documental de primera mano" (pág. 51). Algunas de ellas se presentan a continuación.

Gómez (2012c): en su trabajo de grado titulado "Programa de Sensibilización para la Disminución de las Enfermedades Endémicas del Virus 
Chikungunya en la comunidad La Morita", la necesidad de desarrollar destrezas en los alumnos y demás miembros de la comunidad, de tal manera que proyecten una acción sensibilizadora ante la problemática del virus chikungunya. La metodología empleada fue de tipo descriptiva con apoyo en una investigación de campo. La población la conformaron alumnos, padres y docentes para un total de novecientos cincuenta (950). La técnica empleada fue la encuesta y como instrumento un cuestionario mixto con preguntas abiertas y cerradas.

El autor concluye: la importancia de realizar trabajos educativos de sensibilización dentro de la escuela y la comunidad con la finalidad de establecer alternativas de solución para la situación actual y por consiguiente enriquecer la calidad de vida de la población.

Por su parte, Rozo (2013): en su estudio titulado "Propuesta Metodológica para la Educación en Salud de la Persona, la Familia y la Comunidad". Se planteó como objetivo elaborar una propuesta metodológica con miras a fortalecer la educación para la salud como parte de la formación del profesional de enfermería en su relación con la persona y los colectivos. Los métodos empleados estuvieron enfocados en el histórico lógico, deductivo-inductivo y nivel empírico. La población estuvo constituida por treinta y dos (32) estudiantes de séptimo, treinta y siete (37) estudiantes de octavo y dos (02) profesoras de dos facultades de enfermería.

El autor concluyó que el modelo de enseñanza adoptado en Colombia establece la formación enfocada más a las acciones propias de enfermería, dejando como algo secundario la dimensión educativa y social limitando la posibilidad de desarrollar en una forma integrada las acciones de prevención y promoción de la salud a nivel individual y colectivo.

\subsection{Programa de Formación en Educación para la Salud}

El mundo de hoy demanda la formación de personas con la capacidad 
de desenvolverse de manera fluida, armónica, tomar decisiones, de trabajar con otros, de comunicar sus ideas, gestionar su actuar en vista de metas personales, educativas y laborales, entre otras, en distintos escenarios. Por lo que el tema de la formación integral ha sido objeto de estudio, tanto en organismos internacionales como la UNESCO, así como en aquellos responsables de definir los lineamientos de las instituciones educativas en todos los niveles y, particularmente, en la educación superior; en virtud que la formación integral es uno de los propósitos que deben alcanzarse a través del cumplimiento de las funciones universitarias: docencia, investigación y extensión.

Está comprobado que una formación integral que estimule el desarrollo de habilidades emocionales, sociales y éticas, promueve un mayor bienestar y calidad de la convivencia social, favorece mejores aprendizajes y además ayuda a prevenir que las personas se involucren en conductas de riesgo. Sobre esto Ruíz, (s.f.), señala que:

La formación implica una perspectiva de aprendizaje intencionada, tendiente al fortalecimiento de una personalidad responsable, ética, crítica, participativa, creativa, solidaria y con capacidad de reconocer e interactuar con su entorno para que construya su identidad cultural. Por tanto, busca promover el crecimiento humano a través de un proceso que supone una visión multidimensional de la persona, y tiende a desarrollar aspectos como la inteligencia emocional, intelectual, social, material y ética-valorar. (pág. 11).

Por consiguiente, el programa de formación implica no sólo la adquisición de los conocimientos específicos y las técnicas adecuadas para el ejercicio profesional, sino también requiere la adquisición de actitudes positivas que incidan en la conducta diaria del individuo en las transformaciones y por ende en el perfeccionamiento del bienestar social, ambiental, económico y educativo. 


\subsection{Educación para la Salud}

La Educación para la Salud, entendida como instrumento de promoción, responde, por tanto, al planteamiento más evolucionado de la misma. Implica la superación de los modelos prescriptivos y conductuales una mirada estrictamente sanitaria, presentes aun en nuestro medio hacia una propuesta participativa, holística y de transversalidad en la gestión institucional y pedagógica de las organizaciones escolares, enfatizando las actitudes y comportamientos (valores) de las personas como las responsables de su propia salud.

En este sentido, Nizama (2007): cuando plantea una concordancia entre los diferentes autores sobre salud y educación, quienes señalan que la educación para la salud trata no solo de transmitir información sino también fomentar la motivación, las habilidades personales (sociales, afectivas y cognitivas) y la valoración por sí mismo y por los demás, todas ellas condiciones necesarias para adoptar medidas destinadas al control y la mejora de la salud.

La Organización Mundial de la Salud (OMS, 2009c): menciona que la educación para la salud comprende las oportunidades de aprendizaje creadas conscientemente que suponen una forma de comunicación destinada a mejorar la alfabetización sanitaria, incluyendo el mejoramiento del conocimiento de la población, en relación con el desarrollo de habilidades personales que conduzcan a un estado de bienestar individual y de la comunidad.

\subsection{La Enfermedad del Chikungunya}

El Chikungunya, según La Organización Panamericana de la Salud (2011):

El CHIKV, es un virus ARN que pertenece al género Alfavirus de la familia Togaviridae. El nombre chikungunya deriva de una 
palabra en Makonde, el idioma que habla el grupo étnico Makonde que vive en el sudeste de Tanzania y el norte de Mozambique. Significa a grandes rasgos "aquel que se encorva" y describe la apariencia inclinada de las personas que padecen la característica y dolorosa artralgia. (pág. 3).

El autor refiere que la enfermedad del Chikungunya es un virus que pertenece a la familia Togaviridae, la cual afecta al organismo del individuo a través de dolencias generales en el cuerpo, el doblamiento de las extremidades inferiores; afectando específicamente las articulaciones de las personas. Por su parte, Montero (2014):

Chikungunya es una virosis emergente que se manifiesta como un síndrome febril con artralgias intensas y exantema, causada por un alfavirus transmitido por mosquitos, el virus chikungunya. Esta enfermedad se ha diseminado globalmente en la última década, amenazando con hacerse pandémica y constituyendo una de las mayores virosis emergentes del siglo $\mathrm{XXI}$. El riesgo de epidemias de chikungunya a partir de casos importados resulta especialmente elevado en las Américas, donde los vectores se hallan presentes en número suficiente y la población no posee inmunidad contra el virus. (pág. 2).

El autor refiere que la enfermedad del Chikungunya es un virus que aparece en pleno siglo XXI y que causado grandes estragos en los individuos. La misma se presenta con dolencias profundas en las articulaciones de las personas acompañada de elevadas fiebres continuas; también es trasmitida por mosquitos infectados del virus. Es importante resaltar que la enfermedad ha atacado gran parte de la población de América, en la cual no se ha contado con una efectiva prevención de la misma.

En consecuencia, la epidemia del Chikungunya se ha observado de manera cíclica, porque su distribución geográfica se ha dado de manera mundial; afectando específicamente a países como Asia y África, en la cual dicha epidemia ha dejado numerosas muertes, deficiencia de salud en algunos individuos y por ende un debilitamiento en el aspecto físico de las personas. 
De allí que, se ha considerado una latente preocupación e interés, en una de las enfermedades que se ha pasado a ser una pandemia, en la prevención e implementación de programas de salud para la disminución de la misma.

\subsection{Tipo y Diseño de la Investigación}

El tipo de estudio se focalizó en una investigación acción participante, porque se busca la interacción con los sujetos o informantes claves que se encuentran relacionado con la temática objeto de estudio. Murcia, citado por Hurtado y Toro (2007a), señala: "el término investigación-acción hace referencia a diversos esfuerzos por desarrollar enfoques investigativos que impliquen la participación de las personas que hayan de ser beneficiarias de la investigación y de aquellas con quienes ha de hacerse" (pág. 18). En otras palabras, la investigación acción incide en la participación de los individuos que se encuentran en un contexto y son los que se van a beneficiar en este caso, a la comunidad "Juan Pedro del Corral", municipio Barinas, estado 
Barinas.

En cuanto al diseño de la investigación se enmarcó en un estudio de campo. Al respecto, Márquez (2010), asegura que es: "aquella que se realiza en el propio lugar donde se desarrollan los acontecimientos" (pág. 20). Es decir, los datos son recolectados directamente de la realidad estudiada, en la cual está ocurriendo el fenómeno objeto de estudio.

Es por ello, que los datos se recolectaran por las aseveraciones que realizaron los informantes claves que se describirán en la investigación. Además de ello, el diseño de la investigación de campo también permitió recabar la información de manera más precisa y concisa en el momento de la aplicación del instrumento de recolección de datos primarios. Además, representa el análisis sistemático de los problemas con el propósito de descubrirlo, explicar las causas y efectos, entender su naturaleza y factores constituyentes o predecir su ocurrencia, donde los datos de interés son recogidos en forma directa de la realidad, sin manipular las variables de estudio.

\subsubsection{Fases de la investigación}

La investigación acción participante proporciona a las comunidades y a las agencias de desarrollo un método para analizar y comprender mejor la realidad de la población (sus problemas, necesidades, capacidades, recursos), les permite planificar acciones, medidas para transformarla y mejorarla. Es un proceso que combina la teoría y la actividad, posibilitando el aprendizaje, la toma de conciencia crítica de la población sobre su realidad, su empoderamiento, el refuerzo y ampliación de sus redes sociales, su movilización colectiva y su acción transformadora. En este orden de ideas, se utilizó la propuesta de Hurtado y Toro (2007b), quienes exponen las siguientes etapas: "diagnóstico, planificación, ejecución, evaluación, y sistematización, las cuales se especifican a continuación”. (pág. 120). 
Etapa I: Diagnóstico: El diagnóstico es el principal elemento de detectar, directamente de la realidad, los acontecimientos reales de la situación objeto de estudio, en este caso, la situación que viven los habitantes comunidad "Juan Pedro del Corral" en la prevención de la enfermedad del Chikungunya.

Etapa II: Planificación: Consiste en la sistematización de las acciones que se seguirán en el mejoramiento de la situación estudiada. Se establecen claramente las necesidades de los ciudadanos con el fin de prever, analizar, anticipar e intentar el desarrollo local y futuro. En consecuencia, se planificarán un conjunto de actividades que van en función de formar un programa de formación en educación para la salud a la comunidad Juan Pedro del Corral en la prevención de la enfermedad del Chikungunya.

Etapa III: Ejecución y la Evaluación de las Acciones Planificadas: En esta etapa se pone en marcha la ejecución de las acciones planificadas en un plan de acción que accederán a consolidar un programa de formación en educación para la salud que acceda a la prevención de la enfermedad del Chikungunya.

Etapa IV: Sistematización: Consiste en la reconstrucción de todo el trabajo, es decir, se reflexionará sobre los logros obtenidos en las actividades planificadas y ejecutadas en el plan de acción. Igualmente, permite el seguimiento y control de las acciones que guiaron el desarrollo del trabajo en la comunidad. Dicha sistematización condujo al conjunto de reflexiones finales realizadas en la indagación.

\subsection{Informantes Clave}

Los informantes clave, son aquellas personas que, por sus vivencias, capacidad de empatizar y relaciones que tienen en el campo pueden apadrinar al investigador, convirtiéndose en una fuente importante de información a la vez que le va abriendo el acceso a otras personas y a nuevos escenarios. De 
allí que, se tomaron siete (07) informantes de la comunidad "Juan Pedro del Corral", municipio Barinas, estado Barinas.

\subsection{Técnicas e instrumentos}

La técnica que se utilizó fue la observación, en la cual se empleó notas de campos los detalles de la interacción, haciendo énfasis sobre todo en el lenguaje y connotaciones particulares del sentir local pero las mismas deben esquematizarse de manera que el entrevistado no se sienta presionado por todo lo que dice y hace. Igualmente, se aplicó la técnica de la entrevista usando un guión de preguntas abiertas, indagando en los informantes lo relacionado a un programa de formación en educación para la salud a la comunidad Juan Pedro del Corral en la prevención de la enfermedad del Chikungunya. Se estableció un diálogo cara a cara, pero un diálogo peculiar, asimétrico, donde una de las partes busca recoger informaciones y la otra se presenta como fuente que las proporciones.

\section{Resultados}

La Unidad de análisis relacionada con el programa de formación en educación, categoría formación integral y sub-categoría conocimientos, los datos reflejó el desconocimiento de los informantes en cuanto al manejo de la información relacionada con la enfermedad del Chikungunya. Esto se debe, a que dicha enfermedad fue muy reciente y rápida en Venezuela, especialmente en el municipio Barinas, y la gran mayoría de los individuos no estaban preparados para recibir dicha enfermedad; ocasionando muchos estragos en las familias barinesas.

Por otra parte, la Unidad de prevención de la enfermedad del Chikungunya, categoría de Educación Ambiental y la sub-categoría condiciones ambientales y actividades preventivas se percibe que los informantes consideran que las condiciones de la comunidad están en 
deterioro, debido a que la comunidad no está organizada para atender a las necesidades ambientales, aguas estancadas, aguas negras, contaminación por basura, entre otros. Los Consejos Comunales y la UBCH les falta accionar actividades educativas en beneficio del bienestar social y calidad de vida.

De igual manera, la categoría factibilidad de intervención y subcategoría Acción Educativa, Participación, Apoyo, los informantes revelaron estar dispuestos en participar y colaborar en acciones educativas que vayan en beneficio a la comunidad. Dichas actividades están relacionadas con la enfermedad del Chikungunya, en la cual se forme y capacite a los ciudadanos y ciudadanas en la prevención de la misma.

\section{Reflexiones Finales}

El programa de formación para la salud busca la formación educativa, orientación e información clave en la participación de los individuos en actividades 0 acciones inherentes a la prevención de la salud, bienestar físico, emocional y social de las personas. Asimismo, representa una guía práctica en la cual el sujeto encontrara medidas preventivas, tratamiento, causas, consecuencias, síntomas, diagnóstico, entre otros, específicamente, de la enfermedad del Chikungunya; incidiendo en cambios de actitud, pensamientos positivos hacia formación integral del individuo, con miras a fortalecer, conservar y preservar el ambiente que lo rodea.

La formulación del programa permitió la motivación, incorporación e integración de los integrantes del Consejo Comunal, la UBCH y algunos miembros de la comunidad de Juan Pedro del Corral en cada una de las acciones que fueron debidamente planificadas en el plan de acción. Además, hubo interés, por parte de los pobladores, en asistir a cada una de actividades del programa.

Es importante destacar que durante la ejecución de las actividades se pudo lograr la participación y la organización de los habitantes. Los asistentes 
manifestaron que los talleres cubrieron las expectativas, son de gran utilidad, dado que desconocían la enfermedad del Chikungunya. Igualmente, expresaron que fueron tomados en cuenta para ser formados y orientados en la prevención de dicha enfermedad; incidiendo en cambios de actitud y conocimientos proactivos ante cualquier adversidad.

Las actividades realizadas se evaluaron de manera continua; el control de asistencia a las reuniones, talleres y charlas se hizo por medios de registro de asistencia y actas, las participantes emitían sus opiniones y experiencias en forma oral. En cuanto a la efectividad de los talleres estos se consideraron muy satisfactorios por parte de las participantes quienes manifestaron estar complacidos y recordaron que esta labor debe continuar.

\section{Referencias}

Cárdenas, R. (2010). Salud preventiva. Colombia: Norma.

Duanes, G. (2010). Perspectiva de calidad de la atención médica: Caso de una comunidad indígena al noroeste de México. México: Revista de Salud Pública.

Gómez, L. (2012a,b,c). Programa de sensibilización para la disminución de las enfermedades endémicas del Virus Chikungunya en la comunidad La Morita. Maracay, Venezuela: UNEFA.

Hurtado, I. \& Toro, J. (2007a,b). Paradigmas y métodos de investigación en tiempos de cambio. Venezuela: Editorial CEC, S. A.

Márquez, M. (2010). Metodología de la Investigación. México: McGraw-Hill. Martínez, M. (2006). Ciencia y arte en la metodología cualitativa. México: Trillas.

Montero, A. (2014). Fiebre chikungunya - Una nueva amenaza global. Med Clin (Barc). Recuperado de:

http://dx.doi.org/10.1016/j.medcli.2014.05.031

Nizama, B. (2007). Educación para la salud. Bogotá: ANDERCOP. 
Organización Mundial de la Salud, OMS (2009a,b,c). Salud preventiva. Madrid: Océano.

Organización Panamericana de la Salud (2011). Preparación y respuesta ante la eventual introducción del virus chikungunya en las Américas. Recuperado de:

http://www1.paho.org/hq/dmdocuments/CHIKV Spanish.pdf

Perea, R. (2001). La Educación para la Salud, Reto de Nuestro Tiempo. Educación XX1, número 004. Madrid, España: Universidad Nacional de Educación a Distancia. Recuperado de: http://revistas.uned.es/index.php/educacionXX1/article/viewFile/361/31 $\underline{4}$

Rozo, D. (2013). Propuesta metodológica para la educación en salud de la persona, la familia y la comunidad. Trabajo de Grado de Maestría, publicada, Cuba: Universidad de la Habana.

Ruíz, L. (s.f.). Formación Integral: Desarrollo Intelectual, Emocional, Social y Ético de los Estudiantes. Revista Universitaria de Sonora. Recuperado de: http://www.revistauniversidad.uson.mx/revistas/1919articulo\%204.pdf

Santander, I. (2010). Educación para la salud. México: Trillas.

Universidad Pedagógica Experimental Libertador (2016). Manual de Trabajos de Grado de Especialización y Maestría y Tesis Doctorales. 5ta. Edición. Caracas, Venezuela: FEDUPEL. Recuperado de: https://es.slideshare.net/mirnalitaguirrez/manual-upel-2016-1pdf 


\section{Carmen Yorlet Escalona Belandria}

email: marlenism3@gmail.com

Nacida en la Grita estado Táchira, Venezuela.

Licenciada en Geografía e Historia (2006-2007).

Bachiller en Humanidades en el Liceo Nacional Pedro María Morante. Actualmente se desempeña en el equipo técnico de la Unidad de Primaria de la Secretaría Ejecutiva de Educación del estado Barinas desde 20162017. Además, se ha desempeñado como trabajadora social en la U.G. José Ignacio del Pumar desde 01/08/1995 hasta el 31/12/1995, Facilitadora de Danza en el C.E.I. Bolivariano Francisco Rivas 01/01/2006-07/07/2006, Docente de Cultura C.E.I. Bolivariano Francisco Rivas 2008-2010, Docente de Enlace de Cultura con Educación Inicial de la Secretaría Ejecutiva de Educación 2011-2014, Equipo Técnico Regional de la Universidad Bolivariana de Venezuela 2014-2015. Ha participado en las siguientes jornadas: Recursos para el aprendizaje con material de desecho, Dirección de Educación del 10 al 14 de abril de 1997, Orientaciones terapéuticas para trabajar niños con dificultades motoras, Zona Educativa 28 de noviembre de 1997. Educación sexual, Zona Educativa, Barinas. V Encuentro Regional de Educación Inicial, Zona Educativa, Barinas. Facilitadora de Danza, Zona Educativa, Barinas.

El contenido de este manuscrito se difunde bajo una Licencia de Creative Commons ReconocimientoNoComercial-Compartirlgual 4.0 Internacional 